\title{
Sex differences in lifetime risk and first manifestation of cardiovascular disease: prospective population based cohort study
}

\author{
OPEN ACCESS
}

\begin{abstract}
Maarten J G Leening PhD student ${ }^{123}$, Bart S Ferket assistant professor of cardiovascular epidemiology ${ }^{145}$, Ewout W Steyerberg professor of medical decision making ${ }^{6}$, Maryam Kavousi postdoctoral research associate ${ }^{1}$, Jaap W Deckers professor of cardiology ${ }^{2}$, Daan Nieboer PhD student $^{6}$, Jan Heeringa study coordinator ${ }^{1}$, Marileen L P Portegies PhD student ${ }^{17}$, Albert Hofman professor of epidemiology ${ }^{13}, \mathrm{M}$ Arfan Ikram associate professor of neuroepidemiology ${ }^{147}, \mathrm{M} \mathrm{G}$ Myriam Hunink professor of clinical epidemiology ${ }^{148}$, Oscar $\mathrm{H}$ Franco professor of preventive medicine ${ }^{1}$, Bruno $\mathrm{H}$ Stricker professor of pharmacoepidemiology ${ }^{1910}$, Jacqueline C M Witteman professor of cardiovascular epidemiology ${ }^{1}$, Jolien W Roos-Hesselink professor of cardiology ${ }^{2}$

${ }^{1}$ Department of Epidemiology, Erasmus MC - University Medical Center Rotterdam, Rotterdam, Netherlands; ${ }^{2}$ Department of Cardiology, Erasmus MC - University Medical Center Rotterdam, Rotterdam, Netherlands; ${ }^{3}$ Department of Epidemiology, Harvard School of Public Health, Boston, MA, US; ${ }^{4}$ Department of Radiology, Erasmus MC - University Medical Center Rotterdam, Rotterdam, Netherlands; ${ }^{5}$ Institute of Healthcare Delivery Science, Department of Population Health Science and Policy, Icahn School of Medicine at Mount Sinai, New York, NY, US; ${ }^{6}$ Department of Public Health, Erasmus MC - University Medical Center Rotterdam, Rotterdam, Netherlands; ${ }^{7}$ Department of Neurology, Erasmus MC - University Medical Center Rotterdam, Rotterdam, Netherlands; ${ }^{8}$ Department of Health Policy and Management, Harvard School of Public Health, Boston, MA, US; ${ }^{9}$ Department of Internal Medicine, Erasmus MC - University Medical Center Rotterdam, Rotterdam, Netherlands; ${ }^{10}$ Inspectorate for Health Care, The Hague, Netherlands
\end{abstract}

\author{
Abstract \\ Objective To evaluate differences in first manifestations of cardiovascular \\ disease between men and women in a competing risks framework. \\ Design Prospective population based cohort study. \\ Setting People living in the community in Rotterdam, the Netherlands. \\ Participants 8419 participants ( $60.9 \%$ women) aged $\geq 55$ and free from \\ cardiovascular disease at baseline. \\ Main outcome measures First diagnosis of coronary heart disease \\ (myocardial infarction, revascularisation, and coronary death), \\ cerebrovascular disease (stroke, transient ischaemic attack, and carotid \\ revascularisation), heart failure, or other cardiovascular death; or death \\ from non-cardiovascular causes. Data were used to calculate lifetime \\ risks of cardiovascular disease and its first incident manifestations \\ adjusted for competing non-cardiovascular death.
}

Results During follow-up of up to 20.1 years, 2888 participants developed cardiovascular disease (826 coronary heart disease, 1198 cerebrovascular disease, 762 heart failure, and 102 other cardiovascular death). At age 55, overall lifetime risks of cardiovascular disease were $67.1 \%$ (95\% confidence interval $64.7 \%$ to $69.5 \%$ ) for men and $66.4 \%$ $(64.2 \%$ to $68.7 \%)$ for women. Lifetime risks of first incident manifestations of cardiovascular disease in men were $27.2 \%$ (24.1\% to $30.3 \%)$ for coronary heart disease, $22.8 \%$ (20.4\% to $25.1 \%$ ) for cerebrovascular disease, $14.9 \%$ (13.3\% to $16.6 \%)$ for heart failure, and $2.3 \%$ (1.6\% to $2.9 \%)$ for other deaths from cardiovascular disease. For women the figures were $16.9 \%$ (13.5\% to $20.4 \%$ ), $29.8 \%$ (27.7\% to $31.9 \%), 17.5 \%$ ( $15.9 \%$ to $19.2 \%$ ), and $2.1 \%$ (1.6\% to $2.7 \%$ ), respectively. Differences in the number of events that developed over the lifespan in women compared with men (per 1000) were -7 for any cardiovascular disease, -102 for coronary heart disease, 70 for cerebrovascular disease, 26 for heart failure, and -1 for other cardiovascular death; all outcomes 
manifested at a higher age in women. Patterns were similar when analyses were restricted to hard atherosclerotic cardiovascular disease outcomes, but absolute risk differences between men and women were attenuated for both coronary heart disease and stroke.

Conclusions At age 55, though men and women have similar lifetime risks of cardiovascular disease, there are considerable differences in the first manifestation. Men are more likely to develop coronary heart disease as a first event, while women are more likely to have cerebrovascular disease or heart failure as their first event, although these manifestations appear most often at older ages.

\section{Introduction}

For both men and women, cardiovascular disease remains one of the leading causes of death and disability in Western societies. ${ }^{12}$ Considerable sex differences exist, however, in the occurrence of the various manifestations of cardiovascular disease. Men have a higher risk of coronary heart disease than women, especially at younger ages. ${ }^{3}$ Women, on the other hand, have a similar or greater propensity for developing stroke $\mathrm{e}^{4}$ and heart failure. ${ }^{56}$ Because strategies for prevention of stroke and heart failure might differ from strategies for prevention of coronary heart disease, knowledge about the first manifestation of cardiovascular disease is important for primary prevention purposes. Population based data on sex differences in cardiovascular disease are scarce for the various first manifestations of cardiovascular disease.

Women have a higher life expectancy than men and consequently have more time to develop cardiovascular disease. Cardiovascular risk factors, such as smoking, not only increase the susceptibility for cardiovascular disease but are also associated with an increased risk of dying from non-cardiovascular causes before the development of cardiovascular disease. ${ }^{78}$ Therefore, in comparisons of first manifestations of cardiovascular disease, competing risks among the different manifestations and death from non-cardiovascular causes cannot be neglected. To date no studies have compared multiple first manifestations of cardiovascular disease between men and women in a competing risks framework.

We used long term follow-up data from the prospective population based Rotterdam Study to calculate the lifetime risks of cardiovascular disease and the first incident manifestations of cardiovascular disease in middle aged and elderly men and women.

\section{Methods}

\section{Study design, setting, and population}

This study was performed within the Rotterdam Study, a prospective population based cohort designed to study the occurrence and determinants of age related diseases in the general population. Details regarding the objectives and design have been reported previously. ${ }^{910}$ Briefly, for the initial cohort (RS-I) all inhabitants aged $\geq 55$ from a well defined suburb in the city of Rotterdam, Netherlands, received an invitation to participate, and 7983 (78.1\%) were enrolled. Levels of participation at baseline did not differ for men and women but were lower with increasing age. ${ }^{11}$ From 1990 to 1993 , baseline data were collected during standardised home interviews and two visits to the research centre. Starting in 2000, the Rotterdam Study was extended with a second cohort (RS-II) of inhabitants who reached the age of 55 and people who migrated into the research area since the start of RS-I. A total of 3011 (67.3\%) were enrolled, and baseline data were collected from 2000 to
2001. Besides the minimum age, there were no other criteria for eligibility for participation in either of the cohorts.

For the present analysis, we excluded all participants with a history of cardiovascular disease (coronary heart disease, cerebrovascular disease, or heart failure) at baseline $(n=1421)$, those who did not visit the research centre at baseline for assessment of cardiovascular risk factors $(n=1034)$, those who did not provide, or withdrew, informed consent for collection of follow-up data $(n=76)$, and those without any available follow-up data $(n=44)$. This left a total of 8419 people eligible for the present analysis.

\section{Data collection during follow-up}

Follow-up started at the date of assessment of cardiovascular risk factors at the research centre. Methods for the follow-up and data collection in the Rotterdam Study have been described in detail elsewhere. ${ }^{12}{ }^{13}$ In brief, data on clinical outcomes are collected continuously through an automated follow-up system involving digital linkage of the study database to medical records maintained by general practitioners working in the research area. Moreover, well trained research assistants affiliated with the study regularly check the medical records of each participant by hand for diagnoses of interest. Notes, outpatient clinic reports, hospital discharge letters, electrocardiograms, and imaging results are collected from general practitioner records and hospital records. Subsequently, research physicians independently adjudicate all data on potential events. Afterwards, medical specialists whose judgments are considered decisive review the potential cases. Information on vital status is additionally obtained from the central registry of the municipality of the city of Rotterdam.

\section{Assessment of cardiovascular disease outcomes}

All participants were followed up for the occurrence of incident coronary heart disease, cerebrovascular disease, heart failure, other cardiovascular death, and non-cardiovascular death. Definitions and procedures on the adjudication of cardiovascular outcomes have been described in detail previously. ${ }^{612-14}$ In brief, coronary heart disease was defined as fatal or non-fatal myocardial infarction, surgical or percutaneous coronary revascularisation procedure (as a proxy for unstable or incapacitating angina), or death from coronary heart disease. ${ }^{12}$ Cerebrovascular disease was defined as stroke,,${ }^{13}$ transient ischaemic attack,${ }^{14}$ or carotid revascularisation procedure. In accordance with the guidelines of the European Society of Cardiology heart failure was defined as the combination of typical symptoms and signs, confirmed by objective evidence of cardiac dysfunction or a positive response to initiated treatment. ${ }^{612}$ Other deaths from cardiovascular disease included all cardiovascular mortality other than fatal coronary heart disease or fatal stroke, such as deaths from aortic aneurysms, peripheral vascular disease, valvular heart disease, and pulmonary embolisms. ${ }^{12}$

Hard coronary heart disease was defined as fatal and non-fatal myocardial infarction or definite coronary mortality. Hard cerebrovascular disease was defined as non-haemorrhagic stroke. Other atherosclerotic cardiovascular deaths mainly encompassed deaths from abdominal aortic aneurysms and peripheral vascular disease. These definitions of hard atherosclerotic cardiovascular disease correspond with the endpoints used in clinical trials and guidelines for primary prevention of atherosclerotic cardiovascular disease. 


\section{Assessment of cardiovascular risk factors}

Standardised assessment of anthropometrics, cardiovascular risk factors, and use of drugs at baseline has been described in detail for both RS-I ${ }^{15}$ and RS-II. ${ }^{16}$ In RS-I, diabetes mellitus was defined as a random or post-load serum glucose concentration $\geq 11.1 \mathrm{mmol} / \mathrm{L}$, or the use of drugs to lower blood glucose. In RS-II, diabetes mellitus was defined as a fasting serum glucose concentration $\geq 7.0 \mathrm{mmol} / \mathrm{L}$, a non-fasting serum glucose concentration $\geq 11.1 \mathrm{mmol} / \mathrm{L}$ (only if fasting serum was unavailable), or the use of drugs to lower blood glucose. A family history of premature myocardial infarction was defined as having a parent, sibling, or child who experienced a myocardial infarction at the age of $\leq 65$. Use of drugs to lower blood pressure was defined as the use of antiadrenergics, diuretics, $\beta$ blockers, calcium channel blockers, or renin-angiotensin system modifying agents.

\section{Statistical analysis}

We used linear regression models or Mann-Whitney U tests for continuous data and $\chi^{2}$ tests for categorical data to compare baseline characteristics between men and women.

We calculated remaining lifetime risks for first incident cardiovascular disease and its components (coronary heart disease, cerebrovascular disease, heart failure, and other cardiovascular death) for men and women at age 55, 65, 75, and 85 . When older individuals are followed for longer time periods, death from non-cardiovascular causes precludes the occurrence of cardiovascular disease in many. Similarly, when first manifestations of cardiovascular disease are studied, the occurrence of one manifestation precludes consideration of any subsequent cardiovascular disease event. The preclusion of disease specific outcomes of interest by death or other outcomes are referred to as competing risks. ${ }^{17}{ }^{18}$ Standard application of survival analysis, such as Cox regression and Kaplan-Meier estimates, do not take competing risks into account as those who develop competing events are censored. Consequently, absolute risks are overestimated. ${ }^{17}{ }^{18}$ We therefore used a method that takes into account the occurrence of competing events to compute lifetime cumulative incidences in left truncated data with age as time scale. ${ }^{19}$ This enabled us to compute lifetime risks with only 20.1 years of follow-up. Lifetime risk estimates reflect the cumulative incidences to the age of last observation: in our data the maximum age was 106.4 years for men and 107.0 years for women. In the setting of competing risks analysis, the sum of the lifetime risks of cardiovascular disease and competing non-cardiovascular death equals 1 ; the sum of the lifetime risks of the different first manifestations of cardiovascular disease equals the lifetime risk of cardiovascular disease. ${ }^{17}{ }^{18}$ We computed the excess number of events occurring over the lifespan in women compared with men (per 1000) by subtracting the lifetime risk in men from the lifetime risk in women for each of the manifestations of cardiovascular disease and multiplying it by 1000 .

To evaluate the effect of adjustment for cardiovascular risk factors on sex differences, we quantified the association of sex with the subdistribution hazard of cardiovascular disease (or the specific first manifestations) and non-cardiovascular death using the method proposed by Fine and Gray. ${ }^{20}$ Results are presented for models that were unadjusted (model 1); adjusted for age (as a linear covariate) and level of education (model 2); and additionally adjusted for systolic and diastolic blood pressure, concentrations of total and high density lipoprotein cholesterol, diabetes mellitus, smoking status, family history of premature myocardial infarction, body mass index (BMI), C reactive protein concentration, use of drugs to lower blood pressure, and use of statins (model 3).

Next, we used the data augmentation proposed by Lunn and McNeil to enable direct comparisons between the effect estimates of sex on specific first manifestations of cardiovascular disease by traditional Cox regression. ${ }^{21}$ This allows inference on the difference in cause specific hazard ratios of sex on particular manifestations of cardiovascular disease in the presence of competing manifestations and non-cardiovascular death. ${ }^{18}$ We present $\mathrm{P}$ values from the fully adjusted models (model 3).

To exclude the influence of differences in the inclusion of "softer" events in coronary heart disease and cerebrovascular disease, we then limited the analysis to first incident hard atherosclerotic cardiovascular events.

As a secondary analysis, we also repeated the main analysis with cardiovascular disease categorised as fatal or non-fatal. A first manifestation of cardiovascular disease was considered fatal if death occurred within 28 days of the event and death was attributed to cardiovascular disease.

As participants of RS-II were enrolled six to eight years after the baseline examination of the participants of RS-I, we allowed for strata of cohorts in the regression analyses and repeated all the analysis in each cohort separately. A total of 476 (5.7\%) individuals had missing values for one or more traditional cardiovascular risk factors (range $0-2.5 \%$ per risk factor) and other covariables were missing in up to $3.5 \%$ of the participants. These missing values were handled separately for each cohort by a single imputation with an expectation-maximisation algorithm. ${ }^{22}$ We used the level of significance of $\mathrm{P}<0.05$. All measures of association are presented with $95 \%$ confidence intervals. Data were handled and analysed with the IBM SPSS Statistics version 21.0.0.1 (IBM Corp., Somers, NY), R version 3.0.0 and its libraries "cmprsk," "etm," and "mstate."

\section{Results}

\section{Baseline characteristics}

On average women were older than men and had lower levels of attained education (table $1 \Downarrow$ ). Cholesterol concentrations and BMI were generally higher in women, whereas men had higher diastolic blood pressure and were more often smokers. Several baseline characteristics differed between both cohorts, including an overall increase in the level of highest attained education, higher blood pressure, lower concentrations of total cholesterol, more frequent use of statins, and higher BMI in RS-II. Also, although still significant, sex differences in smoking status were less pronounced in RS-II.

\section{Lifetime risk of cardiovascular disease}

During a total of 81276 person years (median 13.5 years for persons censored alive) of follow-up, 2888 participants developed a cardiovascular disease event, which corresponds to an incidence rate of 35.5 (95\% confidence interval 34.2 to 36.9) per 1000 person years for any first manifestation of cardiovascular disease. Of these 2888 events, 826 were coronary heart disease, 1198 were of cerebrovascular origin, 762 were heart failure, and 102 were other cardiovascular deaths. Of the first cardiovascular disease events, $608(21.1 \%)$ were fatal. Another 1532 individuals died from non-cardiovascular causes, and 20 participants were lost to follow-up over the course of the study (mainly from emigration). In the analysis restricted to hard atherosclerotic outcomes, we included 1700 cardiovascular events, of which 766 were hard coronary heart 
disease, 869 non-haemorrhagic stroke, and 65 other atherosclerotic cardiovascular deaths. Table 2 and appendix table A show details regarding the amount of follow-up and the number of specific events observed in men and women of each cohort. $\Downarrow$

The overall lifetime risk of cardiovascular disease was similar for men and women at the age of 55 (table $3 \Downarrow$, fig $1 \Downarrow$ ), with $67.1 \%$ (95\% confidence interval $64.7 \%$ to $69.5 \%$ ) for men and $66.4 \%$ (64.2\% to $68.7 \%$ ) for women. Remaining lifetime risks of cardiovascular disease decreased with advancing age as the incidence of competing non-cardiovascular death increased. The decrease was larger for men than for women: for those aged 85 without cardiovascular disease the remaining lifetime risk of cardiovascular disease was $52.0 \%$ (46.6\% to $57.3 \%)$ in men and $57.1 \%(53.9 \%$ to $60.3 \%)$ in women. The cumulative incidence of cardiovascular disease in men increased steadily with age, whereas in women up to the age of 70 the cumulative incidence remained low and increased steeply thereafter (fig $1 \Downarrow)$.

\section{First manifestation of cardiovascular disease}

Although the overall lifetime risks of developing any cardiovascular disease were similar for men and women, the first manifestations were different (table $3 \Downarrow$, fig $2 \Downarrow$ ). At age 55, lifetime risks of the first manifestations of cardiovascular disease in men were $27.2 \%$ for coronary heart disease, $22.8 \%$ for cerebrovascular disease, and $14.9 \%$ for heart failure versus $16.9 \%, 29.8 \%$, and $17.5 \%$, respectively, for women. For every 1000 women, this would translate into 102 fewer first manifestations with coronary heart disease developing over the lifespan, but 70 more with cerebrovascular disease and 26 more with heart failure when compared with men. With increasing age, excess risk remained about the same for cerebrovascular disease but decreased for coronary heart disease and heart failure. Cerebrovascular disease and heart failure became the most common initial manifestations for men free from cardiovascular disease at age 75 or higher. In women, cerebrovascular disease was the most common first manifestation in the remaining lifespan at every age. Figure 2 shows the cumulative incidences for the various cardiovascular disease manifestations $\Downarrow$. In men, the cumulative incidence of coronary heart disease is higher than that of cerebrovascular disease and heart failure at all ages with the cumulative incidences of the latter two catching up until age 70 and all curves running about parallel thereafter. In women, the curves were steeper for cerebrovascular disease and heart failure than for coronary heart disease, especially at higher ages, indicating that most cases of cerebrovascular disease and heart failure occurred in the later part of the lifespan. Women were on overage older than men when cardiovascular disease manifested, which was the case for each of the separate cardiovascular disease outcomes (appendix table B). In both men and women, those with coronary heart disease as the first manifestation were the youngest, followed by those in whom cardiovascular disease manifested with cerebrovascular disease and heart failure; those who died from other cardiovascular causes were the oldest.

In line with the pattern of later onset of cardiovascular disease in women shown in figure $1 \Downarrow$, hazards (that is, instantaneous risks) were lower for women than men with respect to any first cardiovascular event or death from non-cardiovascular causes (table $4 \Downarrow$ ). The adjusted cause specific hazard ratio of sex for development of cardiovascular disease was not significantly different from the hazard ratio for competing non-cardiovascular death (Lunn and McNeil $\mathrm{P}=0.33$ for model 3), which corroborates with the comparable lifetime risk of cardiovascular disease. There was a large sex difference in the unadjusted hazards for the development of coronary heart disease as a first manifestation of cardiovascular disease. Also, despite the overall lower hazards of cardiovascular disease, women had a somewhat higher hazard than men for developing cerebrovascular disease but not for heart failure. The age adjusted hazard ratios (model 2) were generally similar to the ones additionally adjusted for traditional and newer cardiovascular risk factors (model 3). Even after adjustment for these risk factors, cause specific hazard ratios for the sex differences remained significantly lower for coronary heart disease than cerebrovascular disease (Lunn and McNeil $\mathrm{P}<0.001$ for model 3) or heart failure (Lunn and $\mathrm{McNeil} \mathrm{P}=0.010$ for model 3). Competing risk regression, with Fine and Gray models, yielded smaller hazard ratios than traditional Cox models for all associations except for cerebrovascular disease (table $4 \Downarrow$ ). Estimates were similar in both cohorts (appendix table C).

\section{Hard atherosclerotic cardiovascular disease}

Lifetime risks for hard atherosclerotic cardiovascular disease were substantially lower than with the broad definition of cardiovascular disease (table $5 \Downarrow$, appendix fig A). For those aged 55, the lifetime risk of atherosclerotic cardiovascular disease was $43.2 \%$ (95\% confidence interval $40.7 \%$ to $45.6 \%$ ) for men and $38.1 \%$ (36.2\% to $40.1 \%$ ) for women. For men and women free from atherosclerotic cardiovascular disease at age 85 , remaining lifetime risks were about $31 \%$. Again sex differences were apparent in the first manifestation of atherosclerotic cardiovascular disease (table $5 \Downarrow$, appendix fig B). At age 55, lifetime risks of first manifestations of atherosclerotic cardiovascular disease were $23.5 \%$ for hard coronary heart disease and $17.8 \%$ for non-haemorrhagic stroke in men versus $14.4 \%$ and $22.5 \%$, respectively, in women. For every 1000 women, this translates into 91 fewer first manifestations of coronary heart disease over the lifetime and 48 more first manifestations of stroke compared with men. In men coronary heart disease was the most common first manifestation in the remaining lifespan except for those aged $\geq 85$, whereas in women stroke was the predominant presentation during the remaining lifespan at all ages, especially in older people. Identical patterns of the first occurrence of atherosclerotic cardiovascular disease outcomes by rising age were observed as were seen for the broad cardiovascular disease outcome, although the cumulative incidence of cerebrovascular disease crossed that of coronary heart disease in women at a somewhat higher age (appendix table D, appendix fig B).

\section{Case fatality}

In both men and women, fatality of the first manifestation of cardiovascular disease increased with age, with women being slightly more likely to have their cardiovascular disease presenting with a fatal event (18.0\% of first events in men aged $\geq 55$ versus $20.9 \%$ in women, $\mathrm{P}=0.047$ ), but this was predominantly because of more fatal events in women at old age (appendix fig $\mathrm{C}$, appendix table $\mathrm{E}$ ). Fatal first manifestations of cardiovascular disease other than coronary heart disease, cerebrovascular disease, or heart failure were rare in all age and sex groups (tables 3 and $5 \Downarrow \Downarrow$ ).

\section{Discussion}

Within a contemporary prospective population based cohort of the general population, we used competing risks analysis to appropriately quantify lifetime risk of cardiovascular disease and its first manifestations in both sexes. At age 55, the risk of 
developing any cardiovascular disease over the lifespan was similar for men and women. We found large sex differences in the initial manifestation of cardiovascular disease. Men are more likely to develop coronary heart disease as a first event, while women are more likely to develop cerebrovascular disease or heart failure as a first event, although these manifestations appear most often at older age.

According to data from various American cohort studies, about $60 \%$ of middle aged men and little over half of the middle aged women develop cardiovascular disease during their remaining lifespan. ${ }^{23}$ We report higher estimates of lifetime cardiovascular risk. These differences can be explained by our inclusion of "softer" cardiovascular manifestations, such as transient ischaemic attack and arterial revascularisation procedures. Such manifestations generally have less impact on the lives of the patients, but do significantly contribute to the overall burden of consumption of healthcare and its associated costs.

An important point to consider is that within the Rotterdam Study one of the soft coronary events, non-invasively managed angina, was not adjudicated. Angina can constitute $34 \%$ of first diagnoses of coronary heart disease in men and $42 \%$ in women, though the contribution of new onset isolated angina to the incidence of coronary heart disease is small after age $70 .{ }^{3}$ Angina is difficult to adjudicate, but based on these estimates of angina, we covered about half of the angina events with the inclusion of coronary revascularisations. These represent the more definite and severe cases of unstable or incapacitating exertional angina. The lack of non-invasively managed angina could have reduced absolute risk difference for coronary heart disease between men and women. We therefore also conducted an analysis restricted to hard cardiovascular outcomes. In this analysis, overall lifetime risk of cardiovascular disease was somewhat lower in women than in men $(38.1 \% v 43.2 \%$ at age 55$)$ and excess risk attenuated for both coronary heart disease and cerebrovascular disease compared with the broad cardiovascular disease endpoint. The pattern of sex differences, however, remained the same: cardiovascular disease presented more often with coronary heart disease in men and more often with cerebrovascular disease in women.

The results of our regression analysis of the sex differences for the various cardiovascular manifestations were not materially affected by adjustment for cardiovascular risk factors (table $4 \Downarrow$ ). This indicates that variation in risk factors between men and women does not explain the observed differences in risk. The pattern of sex differences was less pronounced for first manifestations of cerebrovascular disease based on the hazard ratios compared with lifetime risks, while the sex difference in hazards for heart failure even reversed in the adjusted models. This might be explained by the fact that hazard ratios have a more limited interpretation for the lifetime perspective $\mathrm{e}^{24}$ and even more so after adjustment for age as higher life expectancy in women is one of the driving forces behind a high lifetime risks.

\section{Implications}

The recently released British and American guidelines on primary prevention of cardiovascular disease recognise the importance of assessment of lifetime risk. ${ }^{25}$ Most middle aged women, even those with a moderate to high burden of risk factors, are at (often falsely reassuring) low short term risk of developing cardiovascular disease and thereby might still not qualify for intensive preventive measures based on their global 10 year cardiovascular risk. ${ }^{27-29}$ Our results indicate that many women have a lifetime risk of cardiovascular disease that is similar to that of men. Clinicians should therefore be aware that the risk of cardiovascular disease rises more steeply in women at older age than in men and that a low 10 year risk might come with a high lifetime risk. On the other hand, cardiovascular disease manifests at higher ages in women than in men. Onset of cardiovascular disease at older age might not have the same impact as onset at younger age, which is not accounted for by the use of lifetime risks.

The global cardiovascular risk scoring algorithms that are currently recommended in the prevention guidelines no longer include only coronary heart disease as the outcome of interest. ${ }^{25} 26^{30-32}$ The British and American guidelines now recommend consideration of the risk of stroke besides coronary heart disease to identify people at high risk of cardiovascular disease. ${ }^{25} 2632$ Compared with the older guidelines based on coronary risk, substantially more women will be considered at high risk under these new guidelines and thereby qualify for more intensive risk factor control. ${ }^{33}$ Our results on lifetime risk of hard atherosclerotic cardiovascular disease (hard coronary heart disease and stroke) support this as the estimates were only somewhat lower in women than in men (table $5 \Downarrow$ ). Despite that most attention on current prevention guidelines has focused on the indications for lipid lowering treatment, adequate control of the main modifiable causes of stroke-hypertension and smoking ${ }^{34}$ - should remain top priorities for clinicians and policy makers to reduce the population burden of cerebrovascular disease.

We noticed that heart failure constitutes about a quarter to a third of the first manifestation of cardiovascular disease in both men and women. This is a substantial proportion, especially given that by definition none of the cases of heart failure in our study were preceded by overt coronary heart disease, which is considered to be the most important cause of heart failure in older people. ${ }^{35}$ The high risks and similarity in men and women is in agreement with the results from three American population based cohorts. ${ }^{36}$ In the light of primary prevention of cardiovascular disease this finding once more emphasises the need to also focus on risk factors other than hyperlipidaemia, as lipid lowering treatment has so far not been proved beneficial to reduce the risk of non-ischaemic heart failure. Lifestyle modification and blood pressure control are the main targets for prevention of heart failure, especially in women, in whom blood pressure is known to play a more prominent role in the development of heart failure than in men. ${ }^{37}$

Up to age 75 , first manifestations of cardiovascular disease were rarely fatal in our study, and case fatality of the first manifestation of cardiovascular disease increased with age. The European guidelines for prevention of cardiovascular disease recommend the use of the SCORE algorithm, which can be used to estimate the 10 year risk of fatal cardiovascular disease. ${ }^{30} 31$ A consequence of the use of fatal events only is that treatment allocation, based on absolute risk thresholds from the SCORE algorithm, disproportionately increases the likelihood for older individuals to be considered as candidates for preventive treatment. Unfortunately, the expected absolute benefit from prevention wanes with advancing age because of the increased risk of competing non-cardiovascular death. ${ }^{38} 39$

\section{Limitations}

Our study has some limitations that need to be considered. Various different manifestations of cardiovascular disease were adjudicated according to standardised definitions. We did not have adjudicated events available on incident angina that was managed with non-invasive treatment, non-fatal peripheral 
vascular disease, and non-fatal abdominal aortic aneurysms. Within a subset of the RS-I cohort, surgery for abdominal aortic aneurysms has been adjudicated, which represented only $1.3 \%$ of the first manifestations of cardiovascular disease. Secondly, as our results were obtained from a population aged $\geq 55$ our results cannot be directly generalised to younger individuals who might have an even higher lifetime risk of cardiovascular disease. Thirdly, the Rotterdam Study cohorts are predominantly of European descent (97.8\% white). This is relevant because lifetime risk of cardiovascular disease and its manifestations vary by race. ${ }^{40}$ Fourthly, as the incidence of cardiovascular disease has decreased substantially over the past decades, estimates of lifetime risk are subject to birth cohort effects. We used data from a broad age range (age 55.0 to 106.2 at baseline) with long follow-up (over 20 years) to ensure that individuals from various birth cohorts contribute to different age specific cumulative incidences and thereby reduce these effects. ${ }^{7}$ Also, the long follow-up will mitigate the "healthy volunteer effect" that is known to cause an underestimation of the actual incidence of most diseases shortly after baseline in population based studies that require active participation. ${ }^{41}$ Participation rates at enrolment were similar for men and women in all age groups, ${ }^{11}$ therefore this is unlikely to explain the sex differences we observed. Nonetheless, the lifetime risks of cardiovascular disease in our study could be somewhat underestimated. Fifthly, we did not take into account changes in treatment and risk factors during follow-up in the multivariable regression models. Finally, in younger women myocardial infarction more often presents without the hallmark symptom of chest pain. ${ }^{42}$ This compromises optimal recognition of coronary heart disease in women and might thereby explain part of the observed sex differences in first manifestation of cardiovascular disease in our study.

\section{Conclusions}

Men and women of middle age have similar overall lifetime risks of cardiovascular disease, with two out of three facing some form of cardiovascular disease during their life. These numbers underline that primary prevention of cardiovascular disease is of paramount importance in both men and women. There are, however, considerable differences in the first manifestation of cardiovascular disease, with men being more likely to develop coronary heart disease as a first event, while women are more likely to have cerebrovascular disease or heart failure as their first event, although these manifestations appear most often at older age. Our results underscore the importance of adequate control of risk factors for stroke and heart failure in primary prevention of cardiovascular disease.

The dedication, commitment, and contribution of inhabitants, general practitioners, and pharmacists of the Ommoord district to the Rotterdam Study are gratefully acknowledged.

Contributors: JWR-H and JCMW conceived the study. MJGL, JWD, JH, MLPP, and MAI contributed to the data acquisition. MJGL and BSF did the analyses. All authors contributed in the interpretation of the data. MJGL, BSF, EWS, and DN provided statistical expertise. MJGL wrote the manuscript. BSF, MK, EWS, JWD, DN, JH, MLPP, AH, MAI, MGMH, $\mathrm{OHF}, \mathrm{BHS}, \mathrm{JCMW}$, and JWR-H contributed to the initial critical revision of the manuscript. MJGL, BSF, EWS, JWD, BHS, and JCMW contributed to the critical revision of the manuscript before publication. All authors had full access to all the data (including statistical reports and tables) in the study and can take responsibility for the integrity of the data and the accuracy of the data analysis. BHS is guarantor.

Funding: This work was supported by grants from the Erasmus MC Thorax Foundation (project grant A1 to JWR-H); the Physico Foundation the De Drie Lichten Foundation (project grant 04/14 to MJGL); the Netherlands Organisation for Health Research and Development (ZonMw) and the Netherlands Organisation for Scientific Research (NWO) (ZonMw HTA grant 80-82500-98-10208 to BHS; and Vici grant 918-76-619 to JCMW). MJGL is supported by a Prins Bernhard Cultuurfonds Fellowship award (grant 30140588 to MJGL); MK is supported by the AXA Research Fund; MAI is supported by the Netherlands Heart Foundation (NHF grant 2012T008 to MAI); additional funding was obtained from the Erasmus University Trustfonds. The Rotterdam Study is supported by the Erasmus MC and Erasmus University Rotterdam; the Netherlands Organisation for Scientific Research (NWO); the Netherlands Organisation for Health Research and Development (ZonMw); the Research Institute for Diseases in the Elderly (RIDE); the Netherlands Genomics Initiative (NGI); the Ministry of Education, Culture and Science, the Ministry of Health, Welfare and Sports; the European Commission (DG XII); and the Municipality of Rotterdam. None of the funders had any role in design and conduct of the study; collection, management, analysis, and interpretation of the data; and preparation, review, or approval of the manuscript.

Competing interests: All authors have completed the ICMJE uniform disclosure form at www.icmje.org/coi_disclosure.pdf and declare: MGMH receives grants from the Netherlands Organisation for Health Research and Development (ZonMw), grants from the Technology Foundation the Netherlands (STW), personal fees from Cambridge University Press, grants from National Institutes of Health $(\mathrm{NIH})$, and non-financial support from the European Society of Radiology (ESR); OHF works in ErasmusAGE, a centre for ageing research across the life course funded by Nestlé Nutrition (Nestec), Metagenics, and AXA.

Ethical approval: The Rotterdam Study complies with the Declaration of Helsinki and has been approved by the medical ethics committee according to the Wet Bevolkingsonderzoek: ERGO (Population Screening Act: Rotterdam Study), executed by the Ministry of Health, Welfare and Sports of the Netherlands. All participants provided written informed consent to participate in the study and for information to be obtained from their treating physicians.

Transparency declaration: The manuscript's guarantor affirms that the manuscript is an honest, accurate, and transparent account of the study being reported; that no important aspects of the study have been omitted; and that any discrepancies from the study as planned have been explained.

Data sharing: Data can be obtained on request. Requests should be directed towards the management team of the Rotterdam Study (secretariat.epi@erasmusmc.nl), which has a protocol for approving data requests. Because of restrictions based on privacy regulations and informed consent of the participants, data cannot be made freely available in a public repository.

1 Go AS, Mozaffarian D, Roger VL, Benjamin EJ, Berry JD, Blaha MJ, et al. Heart disease and stroke statistics-2014 update: a report from the American Heart Association. Circulation 2014:129:e28-292

2 Nichols M, Townsend N, Luengo-Fernandez R, Leal J, Gray A, Scarborough P, et al. European cardiovascular disease statistics 2012. European Heart Network, Brussels, European Society of Cardiology, Sophia Antipolis, 2012.

3 Lloyd-Jones DM, Larson MG, Beiser A, Levy D. Lifetime risk of developing coronary heart disease. Lancet 1999;353:89-92.

4 Petrea RE, Beiser AS, Seshadri S, Kelly-Hayes M, Kase CS, Wolf PA. Gender differences in stroke incidence and poststroke disability in the Framingham Heart Study. Stroke 2009;40:1032-7.

5 Lloyd-Jones DM, Larson MG, Leip EP, Beiser A, D'Agostino RB, Kannel WB, et al. Lifetime risk for developing congestive heart failure: the Framingham Heart Study. Circulation 2002;106:3068-72.

6 Bleumink GS, Knetsch AM, Sturkenboom MCJM, Straus SMJM, Hofman A, Deckers JW, et al. Quantifying the heart failure epidemic: prevalence, incidence rate, lifetime risk and prognosis of heart failure: the Rotterdam Study. Eur Heart J 2004;25:1614-9.

7 Lloyd-Jones DM, Dyer AR, Wang R, Daviglus ML, Greenland P. Risk factor burden in middle age and lifetime risks for cardiovascular and non-cardiovascular death (Chicago Heart Association Detection Project in Industry). Am J Cardiol 2007;99:535-40.

8 Störk S, Feelders RA, van den Beld AW, Steyerberg EW, Savelkoul HFJ, Lamberts SWJ, et al. Prediction of mortality risk in the elderly. Am J Med 2006;119:519-25.

9 Hofman A, Grobbee DE, de Jong PTVM, van den Ouweland FA. Determinants of disease and disability in the elderly: the Rotterdam Elderly Study. Eur J Epidemiol 1991;7:403-22. 


\section{What is already known on this topic}

Considerable sex differences exist in the occurrence of manifestations of cardiovascular disease over the lifespan

Competing risks of other manifestations of cardiovascular disease and death from non-cardiovascular causes cannot be neglected in the estimation of risk of specific manifestations of cardiovascular disease

Sex differences in lifetime risk and first manifestation of cardiovascular disease, after adjustment for competing risks, have not been studied

\section{What this study adds}

Two out of three men and women aged 55 will develop cardiovascular disease during their remaining lifespan

There are large differences in the first manifestation of cardiovascular disease: men are more like to develop coronary heart disease as first event, while women are more likely to have cerebrovascular disease or heart failure as their first event, although these manifestations appear most often at older age

Our results underscore the importance of adequate control of risk factors for stroke and heart failure in primary prevention of cardiovascular disease

10 Hofman A, Darwish Murad S, van Duijn CM, Franco OH, Goedegebure A, Ikram MA, et al. The Rotterdam Study: 2014 objectives and design update. Eur J Epidemiol 2013;28:889-926.

11 Hofman A, Boerlage PA, Bots ML, den Breeijen JH, de Bruijn AM, Grobbee DE, et al. [De prevalentie van chronische ziekten bij ouderen; het ERGO-onderzoek]. Ned Tijdschr Geneeskd 1995;139:1975-8.

12 Leening MJG, Kavousi M, Heeringa J, van Rooij FJA, Verkroost-van Heemst J, Deckers JW, et al. Methods of data collection and definitions of cardiac outcomes in the Rotterdam Study. Eur J Epidemiol 2012;27:173-85.

13 Wieberdink RG, Ikram MA, Hofman A, Koudstaal PJ, Breteler MMB. Trends in stroke incidence rates and stroke risk factors in Rotterdam, the Netherlands from 1990 to 2008. Eur J Epidemiol 2012;27:287-95.

14 Bos MJ, van Rijn MJE, Witteman JCM, Hofman A, Koudstaal PJ, Breteler MMB. Incidence and prognosis of transient neurological attacks. JAMA 2007;298:2877-85.

15 Koller MT, Leening MJG, Wolbers M, Steyerberg EW, Hunink MGM, Schoop R, et al. Development and validation of a coronary risk prediction model for older U.S. and European persons in the Cardiovascular Health Study and the Rotterdam Study. Ann Intern Med 2012;157:389-97.

16 Kavousi M, Elias-Smale SE, Rutten JHW, Leening MJG, Vliegenthart R, Verwoert GC et al. Evaluation of newer risk markers for coronary heart disease risk classification: a cohort study. Ann Intern Med 2012;156:438-44.

17 Satagopan JM, Ben-Porat L, Berwick M, Robson M, Kutler D, Auerbach AD. A note on competing risks in survival data analysis. Br J Cancer 2004;91:1229-35.

18 Putter H, Fiocco M, Geskus RB. Tutorial in biostatistics: competing risks and multi-state models. Stat Med 2007;26:2389-430.

19 Meister R, Schaefer C. Statistical methods for estimating the probability of spontaneous abortion in observational studies-analyzing pregnancies exposed to coumarin derivatives. Reprod Toxicol 2008;26:31-5.

20 Fine JP, Gray RJ. A proportional hazards model for the subdistribution of a competing risk. J Am Stat Assoc 1999;94:496-509.

21 Lunn M, McNeil D. Applying Cox regression to competing risks. Biometrics 1995;51:524-32.

22 Dempster AP, Laird NM, Rubin DB. Maximum likelihood from incomplete data via the EM Algorithm. J R Stat Soc B 1977;39:1-38

23 Wilkins JT, Ning H, Berry JD, Zhao L, Dyer AR, Lloyd-Jones DM. Lifetime risk and years lived free of total cardiovascular disease. JAMA 2012;308:1795-801.

24 Hernán MA. The hazards of hazard ratios. Epidemiology 2010;21:13-5.

25 JBS3 Board. Joint British Societies' consensus recommendations for the prevention of cardiovascular disease (JBS3). Heart 2014;100(suppl 2):ii1-ii67.

26 Goff DC Jr, Lloyd-Jones DM, Bennett G, Coady S, D'Agostino RB Sr, Gibbons R, et al. 2013 ACC/AHA guideline on the assessment of cardiovascular risk: a report of the American College of Cardiology/American Heart Association Task Force on Practice Guidelines. Circulation 2014;129(25 suppl 2):S49-73.

27 Marma AK, Lloyd-Jones DM. Systematic examination of the updated Framingham Heart Study general cardiovascular risk profile. Circulation 2009;120:384-90.

28 Cook NR, Paynter NP, Eaton CB, Manson JE, Martin LW, Robinson JG, et al. Comparison of the Framingham and Reynolds Risk scores for global cardiovascular risk prediction in the multiethnic Women's Health Initiative. Circulation 2012;125:1748-56, S1-11.

29 Michos ED, Blumenthal RS. How accurate are 3 risk prediction models in US women? Circulation 2012;125:1723-6.

30 Conroy RM, Pyörälä K, Fitzgerald AP, Sans S, Menotti A, De Backer G, et al. Estimation of ten-year risk of fatal cardiovascular disease in Europe: the SCORE project. Eur Heart J 2003;24:987-1003.

31 Perk J, De Backer G, Gohlke H, Graham IM, Reiner Z, Verschuren WMM, et al. European Guidelines on cardiovascular disease prevention in clinical practice (version 2012). The
Fifth Joint Task Force of the European Society of Cardiology and Other Societies on Cardiovascular Disease Prevention in Clinical Practice (constituted by representatives of nine societies and by invited experts). Developed with the special contribution of the European Association for Cardiovascular Prevention \& Rehabilitation (EACPR). Eur Heart J 2012;33:1635-701.

32 Stone NJ, Robinson JG, Lichtenstein AH, Bairey Merz CN, Blum CB, Eckel RH, et al. 2013 ACC/AHA guideline on the treatment of blood cholesterol to reduce atherosclerotic cardiovascular risk in adults: a report of the American College of Cardiology/American Heart Association Task Force on Practice Guidelines. Circulation 2014;129(25 suppl 2):S1-45.

33 Kavousi M, Leening MJG, Nanchen D, Greenland P, Graham IM, Steyerberg EW, et al. Comparison of application of the ACC/AHA guidelines, Adult Treatment Panel III guidelines, and European Society of Cardiology guidelines for cardiovascular disease prevention in a European cohort. JAMA 2014;311:1416-23.

34 Bos MJ, Koudstaal PJ, Hofman A, Ikram MA. Modifiable etiological factors and the burden of stroke from the Rotterdam Study: a population-based cohort study. PLoS Med 2014;11:e1001634.

35 He J, Ogden LG, Bazzano LA, Vupputuri S, Loria C, Whelton PK. Risk factors for congestive heart failure in US men and women: NHANES I epidemiologic follow-up study. Arch Intern Med 2001;161:996-1002.

36 Huffman MD, Berry JD, Ning H, Dyer AR, Garside DB, Cai X, et al. Lifetime risk for heart failure among white and black Americans: cardiovascular lifetime risk pooling project. $J$ Am Coll Cardiol 2013;61:1510-7.

37 Butler J, Kalogeropoulos AP, Georgiopoulou VV, Bibbins-Domingo K, Najjar SS, Sutton-Tyrrell KC, et al. Systolic blood pressure and incident heart failure in the elderly. The Cardiovascular Health Study and the Health, Ageing and Body Composition Study. Heart 2011;97:1304-11.

38 Ferket BS, van Kempen BJH, Heeringa J, Spronk S, Fleischmann KE, Nijhuis RLG, et al. Personalized prediction of lifetime benefits with statin therapy for asymptomatic individuals: a modeling study. PLoS Med 2012;9:e1001361.

39 Lee SJ, Leipzig RM, Walter LC. Incorporating lag time to benefit into prevention decisions for older adults. JAMA 2013;310:2609-10.

40 Feinstein M, Ning H, Kang J, Bertoni A, Carnethon M, Lloyd-Jones DM. Racial differences in risks for first cardiovascular events and noncardiovascular death: the atherosclerosis risk in communities study, the cardiovascular health study, and the multi-ethnic study of atherosclerosis. Circulation 2012:126:50-9.

41 Leening MJG, Heeringa J, Deckers JW, Franco OH, Hofman A, Witteman JCM, et al. Healthy volunteer effect and cardiovascular risk. Epidemiology 2014;25:470-1.

42 Canto JG, Rogers WJ, Goldberg RJ, Peterson ED, Wenger NK, Vaccarino V, et al. Association of age and sex with myocardial infarction symptom presentation and in-hospital mortality. JAMA 2012;307:813-22.

\section{Accepted: 29 August 2014}

\section{Cite this as: BMJ 2014;349:95992}

This is an Open Access article distributed in accordance with the Creative Commons Attribution Non Commercial (CC BY-NC 4.0) license, which permits others to distribute, remix, adapt, build upon this work non-commercially, and license their derivative works on different terms, provided the original work is properly cited and the use is non-commercial. See: http://creativecommons.org/licenses/by-nc/4.0/. 


\section{Tables}

Table 1| Baseline characteristics of study populations used to determine lifetime risk of cardiovascular disease and its first manifestations. Figures are number of participants (percentage) unless stated otherwise

\begin{tabular}{|c|c|c|c|c|c|c|c|}
\hline & \multirow[b]{2}{*}{ Total $(n=8419)$} & \multicolumn{3}{|c|}{ Rotterdam Study I (1990-93) ( $n=6045)$} & \multicolumn{3}{|c|}{ Rotterdam Study II (2000-01) $(n=2374)$} \\
\hline & & Men $(n=2287)$ & Women $(n=3758)$ & $P$ value & Men $(n=1006)$ & Women $(n=1368)$ & $P$ value \\
\hline Mean (SD) age (years) & $67.6(8.9)$ & $67.9(8.3)$ & $69.7(9.4)$ & $<0.001$ & $63.7(7.1)$ & $64.6(8.0)$ & 0.003 \\
\hline \multicolumn{8}{|l|}{ Education: } \\
\hline Primary & $1568(19.1)$ & $353(15.7)$ & $1024(28.3)$ & \multirow[t]{4}{*}{$<0.001$} & $62(6.3)$ & $129(9.7)$ & \multirow[t]{4}{*}{$<0.001$} \\
\hline $\begin{array}{l}\text { Lower/intermediate general } \\
\text { and lower vocational }\end{array}$ & $3506(42.8)$ & 755 (33.5) & $1702(47.0)$ & & $260(26.2)$ & 789 (59.2) & \\
\hline $\begin{array}{c}\text { Higher general and } \\
\text { intermediate vocational }\end{array}$ & $2221(27.1)$ & 805 (35.8) & $738(20.4)$ & & 395 (39.8) & $283(21.2)$ & \\
\hline $\begin{array}{l}\text { Higher vocational and } \\
\text { university }\end{array}$ & $903(11.0)$ & $338(15.0)$ & $159(4.4)$ & & $275(27.7)$ & $131(9.8)$ & \\
\hline \multicolumn{8}{|c|}{ Mean (SD) blood pressure $(\mathrm{mm} \mathrm{Hg})$ : } \\
\hline Systolic & $140(22)$ & $139(22)$ & $140(22)$ & 0.24 & $144(21)$ & $142(22)$ & 0.077 \\
\hline Diastolic & $75(12)$ & $75(12)$ & $73(11)$ & $<0.001$ & $81(11)$ & $78(10)$ & $<0.001$ \\
\hline $\begin{array}{l}\text { Use of drugs to lower blood } \\
\text { pressure }\end{array}$ & 2201 (26.2) & $474(20.7)$ & $1149(30.6)$ & $<0.001$ & $221(22.0)$ & $357(26.5)$ & 0.013 \\
\hline $\begin{array}{l}\text { Mean (SD) total cholesterol } \\
(\mathrm{mmol} / \mathrm{L})\end{array}$ & $6.4(1.2)$ & $6.3(1.2)$ & $6.8(1.2)$ & $<0.001$ & $5.6(1.0)$ & $6.0(0.9)$ & $<0.001$ \\
\hline $\begin{array}{l}\text { Mean (SD) high density } \\
\text { lipoprotein cholesterol } \\
(\mathrm{mmol} / \mathrm{L})\end{array}$ & $1.4(0.4)$ & $1.2(0.3)$ & $1.4(0.4)$ & $<0.001$ & $1.2(0.3)$ & $1.5(0.4)$ & $<0.001$ \\
\hline Use of statins & 297 (3.5) & $24(1.1)$ & $57(1.5)$ & 0.13 & $82(8.2)$ & $134(9.9)$ & 0.14 \\
\hline Diabetes mellitus & $831(9.9)$ & $214(9.4)$ & $374(10.0)$ & 0.42 & $119(11.8)$ & $124(9.1)$ & 0.029 \\
\hline \multicolumn{8}{|l|}{ Smoking status: } \\
\hline Current & $1912(23.2)$ & $696(31.0)$ & $674(18.5)$ & \multirow[t]{3}{*}{$<0.001$} & $267(26.7)$ & $275(20.5)$ & \multirow[t]{3}{*}{$<0.001$} \\
\hline Former & $3469(42.1)$ & $1361(60.5)$ & $1022(28.1)$ & & $567(56.8)$ & $519(38.6)$ & \\
\hline Never & $2850(34.6)$ & $191(8.5)$ & $1945(53.4)$ & & 165 (16.5) & $549(40.9)$ & \\
\hline $\begin{array}{l}\text { Family history of premature } \\
\text { myocardial infarction }\end{array}$ & $1331(16.4)$ & $326(14.8)$ & $630(17.5)$ & 0.006 & $156(15.8)$ & 219 (16.3) & 0.75 \\
\hline Mean (SD) BMI & 26.5 (3.8) & $25.6(3.0)$ & $26.7(4.0)$ & $<0.001$ & $26.9(3.4)$ & $27.5(4.5)$ & $<0.001$ \\
\hline $\begin{array}{l}\text { Median }(\mathrm{IQR}) \mathrm{C} \text { reactive } \\
\text { protein }\left(\mathrm{mg} / \mathrm{L}^{*}\right)\end{array}$ & 1.57 (0.70 to 3.21$)$ & $1.78(0.83$ to 3.81$)$ & 1.79 (0.89 to 3.30$)$ & 0.23 & $0.90(0.30$ to 2.20$)$ & 1.00 (0.40 to 2.50$)$ & 0.104 \\
\hline
\end{tabular}

$\mathrm{BMI}=$ body mass index, IQR=interquartile range.

*Because of skewed distribution. 
Table 2| First incident cardiovascular events during follow-up in study to determine lifetime risk of cardiovascular disease and its first manifestation. Values are numbers of participants (percentage) unless stated otherwise

\begin{tabular}{|c|c|c|c|}
\hline & \multicolumn{2}{|c|}{ Rotterdam Study I ( $n=6045)$} & Rotterdam Study II $(n=2374)$ \\
\hline & Men ( $n=2287)$ & Women ( $n=3758)$ & Men $(n=1006)$ Wome \\
\hline
\end{tabular}

First incident event

\begin{tabular}{lccccc}
\hline Cardiovascular disease event & $2888(34.3)$ & $1053(46.0)$ & $1491(39.7)$ & $164(16.3)$ & $180(13.2)$ \\
\hline Coronary heart disease & $826(9.8)$ & $361(15.8)$ & $338(9.0)$ & $81(8.1)$ & $46(3.4)$ \\
\hline Myocardial infarction & $417(5.0)$ & $188(8.2)$ & $157(4.2)$ & $44(4.4)$ & $28(2.0)$ \\
\hline Coronary revascularisation & $164(1.9)$ & $81(3.5)$ & $46(1.2)$ & $25(2.5)$ & $12(0.9)$ \\
\hline Coronary artery bypass grafting & $80(1.0)$ & $44(1.9)$ & $17(0.5)$ & $13(1.3)$ & $6(0.4)$ \\
\hline Percutaneous coronary intervention & $84(1.0)$ & $37(1.6)$ & $29(0.8)$ & $12(1.2)$ & $6(0.4)$ \\
\hline Other fatal coronary heart disease & $245(2.9)$ & $92(4.0)$ & $135(3.6)$ & $12(1.2)$ & $6(0.4)$ \\
\hline Cerebrovascular disease & $1198(14.2)$ & $382(16.7)$ & $674(17.9)$ & $44(4.4)$ & $98(7.2)$ \\
\hline Stroke & $725(8.6)$ & $231(10.1)$ & $416(11.1)$ & $23(2.3)$ & $55(4.0)$ \\
\hline Ischaemic stroke & $396(4.7)$ & $133(5.8)$ & $213(5.7)$ & $17(1.7)$ & $33(2.4)$ \\
\hline Haemorrhagic stroke & $72(0.9)$ & $25(1.1)$ & $35(0.9)$ & $2(0.2)$ & $10(0.7)$ \\
\hline Unspecified stroke & $257(3.1)$ & $73(3.2)$ & $168(4.5)$ & $4(0.4)$ & $12(0.9)$ \\
\hline Transient ischaemic attack & $470(5.6)$ & $151(6.6)$ & $256(6.8)$ & $20(2.0)$ & $43(3.1)$ \\
\hline Carotid revascularisation & $3(0.0)$ & $0(0.0)$ & $2(0.1)$ & $1(0.1)$ & $0(0.0)$ \\
\hline Heart failure & $762(9.1)$ & $267(11.7)$ & $430(11.4)$ & $37(3.7)$ & $28(2.0)$ \\
\hline Other cardiovascular death & $102(1.2)$ & $43(1.9)$ & $49(1.3)$ & $2(0.2)$ & $8(0.6)$ \\
\hline Non-cardiovascular death & $1532(18.2)$ & $573(25.1)$ & $791(21.0)$ & $93(9.2)$ & $75(5.5)$ \\
\hline No event (censored alive) & $3999(47.5)$ & $661(28.9)$ & $1476(39.3)$ & $749(74.5)$ & $1113(81.4)$ \\
\hline Follow-up time & & & & & 7.9 \\
\hline Total person time (person years) & 81276 & 22769 & 42234 & 6709 & 9564 \\
\hline Median (IQR) (years) & $8.6(5.9$ to 14.9) & $10.5(4.8$ to 15.3) & $13.2(6.2$ to 16.0) & $7.2(5.9$ to 8.3$)$ & $7.4(6.3$ to 8.4$)$ \\
\hline Median (IQR) for participants censored alive (years) & $13.5(7.7$ to 16.2) & $16.0(15.1$ to 16.7) & $16.2(15.2$ to 17.1) & $7.7(6.8$ to 8.4) & $7.7(6.7$ to 8.4) \\
\hline IQR=interquartile range. & & & & & \\
\hline & & & & & \\
\hline
\end{tabular}




\begin{tabular}{|c|c|c|c|c|}
\hline \multirow[b]{2}{*}{ Age (years) and manifestation } & \multicolumn{2}{|c|}{ Lifetime risk $(\%)^{\star}(95 \% \mathrm{Cl})$} & \multirow[b]{2}{*}{$P$ value } & \multirow[b]{2}{*}{ Excess events per 1000 women } \\
\hline & Men & Women & & \\
\hline \multicolumn{5}{|l|}{ Age 55: } \\
\hline No of people & 3293 & 5126 & - & - \\
\hline Cardiovascular disease & 67.1 (64.7 to 69.5$)$ & $66.4(64.2$ to 68.7$)$ & 0.34 & -7 \\
\hline Coronary heart disease $\neq$ & 27.2 (24.1 to 30.3 ) & 16.9 (13.5 to 20.4$)$ & $<0.001$ & -102 \\
\hline Cerebrovascular disease $\S$ & 22.8 (20.4 to 25.1$)$ & 29.8 (27.7 to 31.9$)$ & $<0.001$ & 70 \\
\hline Heart failure & $14.9(13.3$ to 16.6$)$ & 17.5 (15.9 to 19.2$)$ & 0.014 & 26 \\
\hline 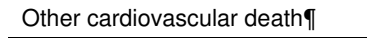 & $2.3(1.6$ to 2.9$)$ & 2.1 (1.6 to 2.7$)$ & 0.39 & -1 \\
\hline \multicolumn{5}{|l|}{ Age 65: } \\
\hline No of people & 3001 & 4832 & - & - \\
\hline Cardiovascular disease & $63.4(61.1$ to 65.7$)$ & 65.6 (63.7 to 67.5$)$ & 0.077 & 22 \\
\hline Coronary heart disease $\neq$ & 21.6 (19.6 to 23.6$)$ & $14.7(13.3$ to 16.2$)$ & $<0.001$ & -69 \\
\hline Cerebrovascular disease & 22.7 (20.7 to 24.7 ) & 30.3 (28.4 to 32.1$)$ & $<0.001$ & 76 \\
\hline Heart failure & $16.8(15.0$ to 18.5$)$ & 18.2 (16.7 to 19.7$)$ & 0.113 & 14 \\
\hline Other cardiovascular death & $2.4(1.6$ to 3.1$)$ & $2.4(1.8$ to 3.0$)$ & 0.49 & 0 \\
\hline \multicolumn{5}{|l|}{ Age 75: } \\
\hline No of people & 1648 & 3180 & - & - \\
\hline Cardiovascular disease & 58.7 (55.8 to 61.6$)$ & $63.4(61.2$ to 65.6$)$ & 0.006 & 48 \\
\hline Coronary heart disease $\ddagger$ & $15.4(13.2$ to 17.5$)$ & 12.5 (11.0 to 14.0$)$ & 0.014 & -29 \\
\hline Cerebrovascular disease $\S$ & 21.9 (19.4 to 24.3$)$ & $28.9(26.8$ to 31.0$)$ & $<0.001$ & 70 \\
\hline Heart failure & 18.3 (16.0 to 20.6$)$ & 19.4 (17.6 to 21.2$)$ & 0.24 & 11 \\
\hline 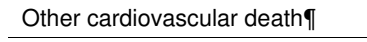 & $3.1(2.1$ to 4.2$)$ & $2.7(2.0$ to 3.5$)$ & 0.26 & -4 \\
\hline \multicolumn{5}{|l|}{ Age 85: } \\
\hline No of people & 438 & 1296 & - & - \\
\hline Cardiovascular disease & 52.0 (46.6 to 57.3$)$ & 57.1 (53.9 to 60.3$)$ & 0.054 & 51 \\
\hline Coronary heart disease $\neq$ & $11.0(7.6$ to 14.3$)$ & $11.6(9.6$ to 13.7$)$ & 0.38 & 6 \\
\hline Cerebrovascular disease $\S$ & $19.3(15.1$ to 23.5$)$ & 24.8 (22.0 to 27.6$)$ & 0.017 & 55 \\
\hline Heart failure & $17.3(13.2$ to 21.3$)$ & $17.9(15.5$ to 20.4$)$ & 0.40 & 6 \\
\hline Other cardiovascular death $\uparrow$ & $4.4(2.2$ to 6.6$)$ & 2.8 (1.7 to 3.9$)$ & 0.095 & -16 \\
\hline
\end{tabular}

*Adjusted for competing non-cardiovascular death.

$\dagger$ Excess risk computed as absolute difference in remaining lifetime risk between men and women.

¥Coronary heart disease=myocardial infarction, coronary revascularisation, or death from coronary heart disease.

$\S$ Cerebrovascular disease=stroke, transient ischaemic attack, or carotid revascularisation.

ๆOther cardiovascular death=all cardiovascular mortality other than fatal coronary heart disease or stroke. 
Table 4| Hazard ratios (95\% confidence intervals) for risk of first incident cardiovascular disease event and non-cardiovascular death for women compared with men (reference category). All regression analyses used follow-up time as time scale and were stratified on cohort (see appendix table $\mathrm{C}$ for results per cohort)

Model 1 (unadjusted)

Traditional Cox model

Competing risks model*

Cardiovascular disease

\begin{tabular}{ll}
$0.75(0.70$ to 0.81$)$ & $0.81(0.76$ to 0.88$)$ \\
$0.48(0.42$ to 0.55$)$ & $0.52(0.46$ to 0.60$)$ \\
\hline $0.99(0.88$ to 1.12$)$ & $1.15(1.02$ to 1.29$)$ \\
\hline $0.83(0.72$ to 0.96$)$ & $0.95(0.82$ to 1.09$)$ \\
\hline $0.67(0.45$ to 1.00$)$ & $0.79(0.53$ to 1.17$)$ \\
\hline $0.68(0.61$ to 0.75$)$ & $0.78(0.71$ to 0.86$)$
\end{tabular}

Coronary heart disease†

$0.68(0.61$ to 0.75$)$

\section{Model 29}

\begin{tabular}{|c|c|c|}
\hline Cardiovascular disease & $0.62(0.57$ to 0.67$)$ & 0.73 (0.67 to 0.79$)$ \\
\hline Coronary heart disease $†$ & 0.42 (0.37 to 0.49$)$ & 0.50 (0.43 to 0.58$)$ \\
\hline Cerebrovascular disease $\neq$ & $0.83(0.73$ to 0.93$)$ & $1.06(0.94$ to 1.20$)$ \\
\hline Heart failure & 0.62 (0.53 to 0.72$)$ & 0.79 (0.68 to 0.93$)$ \\
\hline Other cardiovascular death§ & $0.53(0.35$ to 0.80$)$ & $0.72(0.48$ to 1.09$)$ \\
\hline Non-cardiovascular death & $0.51(0.46$ to 0.57$)$ & $0.67(0.60$ to 0.74$)$ \\
\hline \multicolumn{3}{|l|}{ Model $3^{\star *}$} \\
\hline Cardiovascular disease & 0.68 (0.62 to 0.75$)$ & 0.76 (0.69 to 0.83$)$ \\
\hline Coronary heart disease $\dagger$ & 0.45 (0.37 to 0.53$)$ & $0.51(0.43$ to 0.60$)$ \\
\hline Cerebrovascular disease $\neq$ & $0.96(0.83$ to 1.11$)$ & $1.16(1.00$ to 1.33$)$ \\
\hline Heart failure & 0.62 (0.52 to 0.75$)$ & 0.73 (0.61 to 0.88$)$ \\
\hline Other cardiovascular death§ & $0.73(0.44$ to 1.19$)$ & $0.96(0.61$ to 1.50$)$ \\
\hline Non-cardiovascular death & $0.63(0.55$ to 0.71$)$ & 0.76 (0.66 to 0.87$)$ \\
\hline
\end{tabular}

*Fine and Gray method for subdistribution regression with competing risks. ${ }^{20}$

†Coronary heart disease $=$ myocardial infarction, coronary revascularisation, or death due to coronary heart disease.

¥Cerebrovascular disease=stroke, transient ischaemic attack, or carotid revascularisation.

§Other cardiovascular death=all cardiovascular mortality other than fatal coronary heart disease or stroke.

ๆAdjusted for age (linear covariate) and level of education.

${ }^{* \star}$ Adjusted for age (linear covariate), level of education, systolic and diastolic blood pressure, concentrations of total and high-density lipoprotein cholesterol, diabetes mellitus, smoking status, family history of premature myocardial infarction, body mass index, concentration of C-reactive protein, use of drugs to lower blood pressure, and use of statins. 


\begin{tabular}{|c|c|c|c|c|}
\hline \multirow[b]{2}{*}{ Age (years) and manifestation } & \multicolumn{2}{|c|}{ Lifetime risk $(\%)^{\star}(95 \% \mathrm{Cl})$} & \multirow[b]{2}{*}{$P$ value } & \multirow{2}{*}{$\begin{array}{c}\text { Excess events pe } \\
1000 \text { woment }\end{array}$} \\
\hline & Men & Women & & \\
\hline \multicolumn{5}{|l|}{ Age 55: } \\
\hline No of people & 3293 & 5126 & - & - \\
\hline Hard atherosclerotic cardiovascular event & $43.2(40.7$ to 45.6$)$ & 38.1 (36.2 to 40.1$)$ & $<0.001$ & -51 \\
\hline Hard coronary heart diseaseł & 23.5 (21.4 to 25.6$)$ & $14.4(13.0$ to 15.8$)$ & $<0.001$ & -91 \\
\hline Non-haemorrhagic stroke & $17.8(15.8$ to 19.7$)$ & 22.5 (20.8 to 24.2$)$ & $<0.001$ & 48 \\
\hline Other atherosclerotic cardiovascular death§ & $1.9(1.3$ to 2.6$)$ & $1.2(0.8$ to 1.6$)$ & 0.037 & -7 \\
\hline \multicolumn{5}{|l|}{ Age 65: } \\
\hline No of people & 3159 & 5003 & - & - \\
\hline Hard atherosclerotic cardiovascular event & 40.3 (38.0 to 42.7$)$ & 37.8 (35.8 to 39.7$)$ & 0.050 & -26 \\
\hline Hard coronary heart disease $\ddagger$ & 20.8 (18.8 to 22.7$)$ & $13.7(12.3$ to 15.1$)$ & $<0.001$ & -70 \\
\hline Non-haemorrhagic stroke & $17.7(15.8$ to 19.5$)$ & 22.8 (21.0 to 24.5$)$ & $<0.001$ & 51 \\
\hline Other atherosclerotic cardiovascular death§ & $1.9(1.3$ to 2.6$)$ & $1.3(0.8$ to 1.7$)$ & 0.057 & -6 \\
\hline \multicolumn{5}{|l|}{ Age 75: } \\
\hline No of people & 1934 & 3560 & - & - \\
\hline Hard atherosclerotic cardiovascular event & 35.5 (32.7 to 38.3$)$ & $36.2(34.1$ to 38.4$)$ & 0.34 & 7 \\
\hline Hard coronary heart disease $\ddagger$ & $16.8(14.6$ to 18.9$)$ & $11.9(10.5$ to 13.4$)$ & $<0.001$ & -48 \\
\hline Non-haemorrhagic stroke & $16.7(14.5$ to 18.8$)$ & 22.9 (21.0 to 24.8$)$ & $<0.001$ & 62 \\
\hline Other atherosclerotic cardiovascular death§ & $2.1(1.3$ to 2.9$)$ & $1.4(0.9$ to 1.9$)$ & 0.093 & -6 \\
\hline \multicolumn{5}{|l|}{ Age 85: } \\
\hline No of people & 594 & 1619 & - & - \\
\hline Hard atherosclerotic cardiovascular event & $31.4(26.9$ to 35.8$)$ & $31.6(28.9$ to 34.4$)$ & 0.46 & 3 \\
\hline Hard coronary heart disease $\ddagger$ & $14.1(10.8$ to 17.4$)$ & $10.3(8.5$ to 12.1$)$ & 0.023 & -38 \\
\hline Non-haemorrhagic stroke & $15.9(12.4$ to 19.4$)$ & $20.2(17.8$ to 22.5$)$ & 0.026 & 42 \\
\hline Other atherosclerotic cardiovascular death§ & $1.3(0.3$ to 2.4$)$ & $1.2(0.5$ to 1.8$)$ & 0.41 & -1 \\
\hline
\end{tabular}

*Adjusted for competing non-atherosclerotic death among men and women at different ages.

†Excess risk computed as absolute difference in remaining lifetime risk between men and women.

¥Hard coronary heart disease=myocardial infarction or death from coronary heart disease.

§Other atherosclerotic cardiovascular death=all atherosclerotic cardiovascular mortality other than fatal coronary heart disease or non-haemorrhagic stroke. 


\section{Figures}

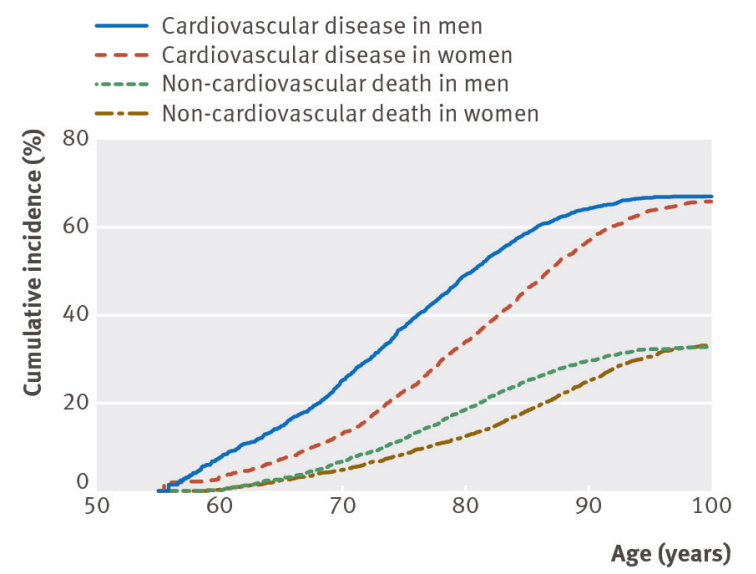

Fig 1 Cumulative incidence of cardiovascular disease (defined as coronary heart disease, cerebrovascular disease, heart failure, and other cardiovascular death) and competing non-cardiovascular death for men and women aged 55. Coronary heart disease was defined as myocardial infarction, coronary revascularisation, or death from coronary heart disease. Cerebrovascular disease was defined as stroke, transient ischaemic attack, or carotid revascularisation. Other cardiovascular death included all cardiovascular mortality other than fatal coronary heart disease or stroke

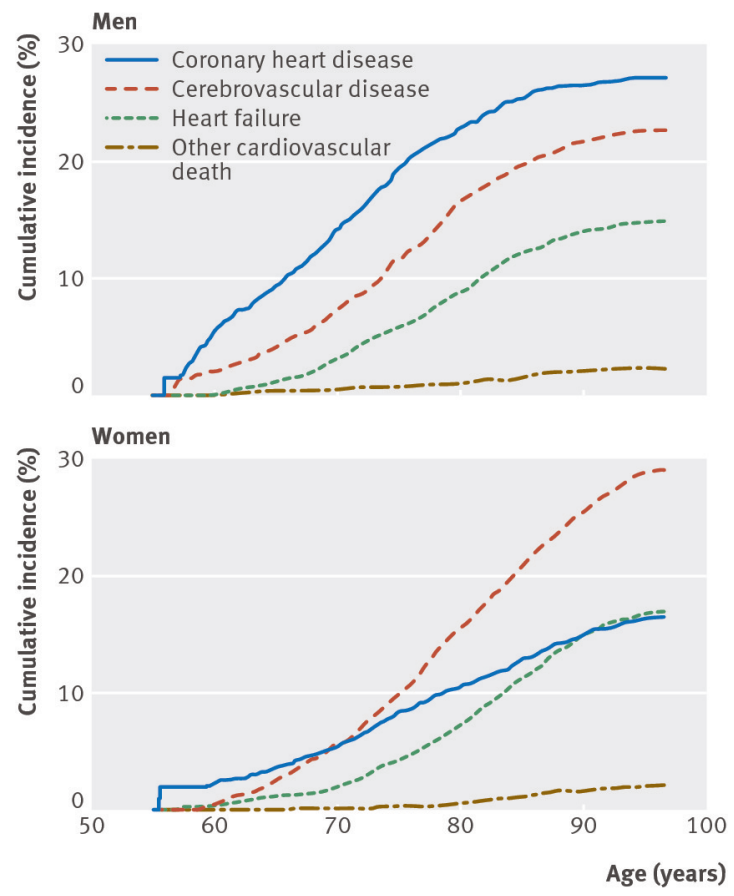

Fig 2 Cumulative incidence of first cardiovascular disease manifestations adjusted for competing non-cardiovascular death for men (left) and women (right) aged 55. Coronary heart disease was defined as myocardial infarction, coronary revascularisation, or death from coronary heart disease. Cerebrovascular disease was defined as stroke, transient ischaemic attack, or carotid revascularisation. Other cardiovascular death included all cardiovascular mortality other than fatal coronary heart disease or stroke 